자연자산의 가치를 반영한 생태계보전협력금 제도 개선 방안

- 산림지역을 중심으로 -

\author{
박진한 $^{1)} \cdot$ 이동근 $^{2)} \cdot$ Tanaka Riwako ${ }^{1)} \cdot$ 김정택 $^{3)} \cdot$ 전성우 $^{4)} \cdot$ 이우균 $^{5)} \cdot$ 김준순 $^{3)} \cdot$ 정태용 $^{6)}$ \\ 1) 서울대학교 대학원 생태조경학전공 ${ }^{2)}$ 서울대학교 조경·지역시스템공학부 · \\ 3) 강원대학교 산림경영학과 · ${ }^{4)}$ 한국환경정책 · 평가연구원 · \\ ${ }^{5)}$ 고려대학교 환경생태공학부 · ${ }^{0} \mathrm{KDI}$ 국제정책대학원
}

\title{
Improvement of Cooperation Charge on Conservation of Ecosystem Reflected Natural Capitals Valuation
}

\author{
- Focused on Forest Area -
}

\author{
Park, Jin-Han $^{1)} \cdot$ Lee, Dong-Kun $^{2)} \cdot$ Tanaka Riwako $^{1)} \cdot$ Kim, Jung-Taek $^{3)} \cdot$ Jeon, Seong-Woo ${ }^{4)}$ \\ Lee, Woo-Kyun ${ }^{5)} \cdot$ Kim, Joon-Soon ${ }^{3)}$ and Jung, Tae-Yong' \\ ${ }^{1)}$ Dept. of Landscape Architecture, Graduate School of Seoul National University, \\ ${ }^{2)}$ Dept. of Landscape Architecture and Rural System Engineering, Seoul National University, \\ ${ }^{3)}$ Dept. of Forest management, Kangwon National University, ${ }^{4)}$ Korea Environment Institute, \\ ${ }^{5)}$ Dept. of Environmental Science and Ecological Engineering, Korea University, \\ ${ }^{6)}$ KDI School of Public Policy and Management.
}

\begin{abstract}
In Korea, a cooperation charge on conservation of ecosystem is imposed to prevent indiscriminate development. The total amount of this charge is determined by multiplying the size of the destroyed area by a value per unit area and the area index within 5 billion won. Since 2001, the charge per unit area has been determined to be 250 won $/ \mathrm{m}^{2}$. In this study, we estimated the unit value of

* 본 연구는 2013년도 환경부 차세대 에코이노베이션 기술 개발사업(과제번호 : 2012-00021-0001, 416-111-015)의 지원으로 수행되었습니다.

First author : Park, Jin-Han, Graduate School of Seoul National University,

Tel : +82-2-880-4885, E-mail : cupid83@snu.ac.kr

Corresponding author: Jeon, Seong-Woo, Korea Environment Institute

Tel : +82-2-380-7661, E-mail : swjeon@kei.re.kr

Received : 18 December, 2013. Revised : 10 February, 2014. Accepted : 17 February, 2014.
\end{abstract}


ecosystem services per year using benefit transfer method, with a focus on forest resources. According to our results, forest resources have a value of about 3,500 won $/ \mathrm{m}^{2}$ per year. When the non-use value is subtracted, that figure becomes approximately $1,300 \mathrm{won} / \mathrm{m}^{2}$. If this value incorporates the unit value of the cooperation charge on conservation of ecosystem, it will increase. To comply with the original intent of the cooperation charge on conservation of ecosystem, the fund must be used to improve ecosystem services, including the restoration of a destroyed area or the purchase of new land.

Key Words : Ecosystem service, Valuation, Assessment of ecosystem, Forest resources, Natural environment conservation Act, Benefit transfer method.

\section{I. 서 론}

생태계의 동 - 식물들은 인간에게 음식, 섬유, 연료, 유전물질, 약효의 원료 등 다양한 혜택을 제공한다. 전 세계적으로 생물다양성에 관한 협 약 등 이러한 생태계를 보호하고 생물다양성을 보전하려는 움직임이 감지되고 있으며, 보이지 않는 생태계의 가치를 평가하려는 연구 또한 활 발히 진행되고 있다(Fisher et al., 2009; Seppelt et al., 2011)

우리나라에서도 무분별한 개발 사업으로 인 해 발생하는 생태계의 파괴를 줄이기 위해 2001 년부터 생태계보전협력금을 부과 - 징수하기 시 작하였다(Ministry of Environment, 2007). 생태 계보전협력금은 자연환경보전법에 의거하여 환 경영향평가대상사업, 광업법 규정에 의한 채굴 사업, 그 밖에 생태계에 미치는 영향이 현저하 거나 자연자산을 이용하는 사업 중 대통령령이 정하는 사업 등을 부과대상으로 한다(National Legislation Information Center). 하지만 이는 무 분별한 개발 사업을 막으려는 본래의 취지와 맞 지 않게 대규모사업에만 적용되어 난개발을 조 장할 우려가 발생한다(Kwak and Yoo, 2000).

특히 2001년 생태계 훼손면적 기준으로 생태 계보전협력금의 부과 방식이 변경될 때 결정된 단위면적당 부과액 $\left(250\right.$ 원 $\left./ \mathrm{m}^{2}\right)$ 이 현재까지 변하
지 않고 그대로 적용되고 있으며, 이에 부담금 을 현실화시키기 위해 단위면적당 부과액을 상향 조정해야 한다는 주장이 제기되고 있다(Ministry of Environment, 2007; Lee, 2009).

본 연구의 목적은 산림 자원을 중심으로 자연 자산의 가치를 반영한 생태계보전협력금의 단 위면적당 부과액을 새롭게 제시하는 데 있으며, 이를 위한 연구의 전체적인 흐름은 먼저 생태계 보전협력금 제도의 개선을 위하여 제도 고찰 및 국내·외 유사 법규와 제도를 조사하여 현행 단 위면적당 부과액의 적정성을 검토한다. 그 후 산림자원이 제공하는 서비스와 서비스별 가치 를 선행연구를 통하여 추정하고, 최종적으로 산 림자원이 제공하는 생태계서비스의 단위가치 및 총가치를 추정한다. 마지막으로 추정된 산림 자원의 가치를 반영한 새로운 단위면적당 부과 액을 제시한다.

\section{II. 생태계보전협력금과 국내·외 유사 법규 및 제도}

\section{1. 생태계보전협력금 개요}

생태계보전협력금은 2001년 1월부터 시행되 었으며 「자연환경보전법」제 5 장 제 46 조 1 항에 따르면 자연환경 또는 생태계에 미치는 영향이 현저하거나 생물다양성의 감소를 초래하는 사 
업을 하는 사업자에 대하여 환경부장관이 부담 금을 부과 - 징수하는 것을 말한다. 또한 이러한 생태계보전협력금은 환경부가 주관하고 지방자 치단체가 부과 및 징수기관의 역할을 하며, 징 수된 금액은 생태계보전 및 복원사업의 지원에 사용된다.

생태계보전협력금의 부과대상이 되는 사업은 「환경영향평가법, 제 9 조에 따른 전략환경영향 평가 대상사업, $「$ 환경영향평가법, 제 22 조 및 제 42 조에 따른 환경영향평가대상사업, 「광업법」 제 3 조 제 2 호에 따른 광업 중 노천탐사 채굴사 업, 환경영향평가법, 제 43 조에 따른 소규모 환 경영향평가 대상 개발사업, 그 밖에 생태계에 미치는 영향이 현저하거나 자연자산을 이용하 는 사업 등을 부과대상으로 하며, 납부의무자는 사업시행자이다.

생태계보전협력금 산정 기준과 산정 방법은 부과대상사업의 인 - 허가 등의 처분 시점을 부 과 시점으로 하여 50 억 원의 범위 안에서 생태 계 훼손면적에 단위면적당 부과액과 지역계수 를 곱하여 아래 Equation 1과 같이 산정금액을
부과한다.

the dagamed area of ecosystem

$\times$ the amount levied per unit of area

$\times$ the regional coefficient

$<$ Equation 1>

지역계수는 r국토의 계획 및 이용에 관한 법률」 에 의한 토지의 용도를 기준으로 하며 그 구체적 인 계수와 부과금 산정 기준은 다음 Table 1 의 내 용과 같다.

한편 징수된 생태계보전협력금은 자연환경보 전법에 따라 환경개선특별회계에 편입시켜 사용 한다. 환경개선특별회계에 편입된 생태계보전협 력금 징수금의 $50 \%$ 는 지자체에 다시 교부되고, 나머지 50\%는 생태계보전협력금 반환사업에 사 용하도록 규정되어 있다. 또한 생태계보전협력 금 교부금은 자연환경보전법과 동법 시행령 규 정에 따라 생태계 생물종의 보전 복원사업, 서식 지외 보전기관의 지원, 생태 경관보전지역 관리 기본계획의 시행, 생태계보전을 위한 토지의 확 보 등을 위하여 사용하도록 규정되어 있다.

Table 1. Cooperation charge on conservation of ecosystem.

\begin{tabular}{|c|c|c|}
\hline \multicolumn{2}{|l|}{ Criteria } & Related Act \\
\hline \multicolumn{2}{|c|}{$\begin{array}{l}\text { - The damaged area of ecosystem } \\
\text { - The amount levied per unit of area: } 250 \mathrm{won} / \mathrm{m}^{2} \\
\text { - The regional coefficient }\end{array}$} & \multirow{8}{*}{$\begin{array}{c}\text { Natural Environment } \\
\text { Conservation } \\
\text { Act } \\
\text { Article } 46 \\
\text { Enforcement } \\
\text { Decree } \\
\text { Article } 38\end{array}$} \\
\hline $\begin{array}{l}\text { Residential area, commercial area, } \\
\text { industrial area or planned management* }\end{array}$ & 1 & \\
\hline Greenbelt area & 2 & \\
\hline Production management area & 2.5 & \\
\hline Agriculture and forestry area & 3 & \\
\hline Conservation management area & 3.5 & \\
\hline Natural environmental conservation area & 4 & \\
\hline \multicolumn{2}{|c|}{$\begin{array}{l}\text { * Where the land category under the Cadastral Act constitutes dry paddy field, } \\
\text { paddy field, forestry, saltern, river, marsh or park; } 1 \text {, in the case of other } \\
\text { land categories; } 0\end{array}$} & \\
\hline
\end{tabular}

* National Legislation Information Center (http://law.go.kr/) 


\section{2. 국내·외 유사 법규 및 제도}

\section{1) 국내 유사 법규 및 제도}

생태계보전협력금과 같은 부담금을 부과하는 유사 법규 및 제도는 대체산림자원조성비, 농지 보전부담금, 대체초지 조성비, 해양생태계보전 협력금, 개발제한구역 보전 부담금 등이 있으며, 그 내용은 다음과 같다.

대체산림자원조성비의 부과 근거는 「산지관 리법」제 19 조에 의거하며, 그 정의는 산지 전용 과 산지 일시 사용에 따른 대체산림자원 조성에 드는 비용을 말하며, 산림청장이 부과·징수한 다. 대체산림자원조성비의 산정 방법은 산지 전 용 또는 일시 사용되는 면적에 단위면적당 금액 을 곱한 금액으로 한다. 단위면적당 금액은 해 당 연도의 잣나무 조림비와 식재 후 10 년까지의 숨가꾸기 비용을 합한 금액과 산림이 가지는 수 원함양 - 대기정화 - 토사유출방지 - 온실가스흡 수 등의 공익적 가치평가액 및 $\mathrm{r}$ 부동산 가격공 시 및 감정평가에 관한 법률」에 따른 해당 산지 의 공시지가를 고려하여 산림청장이 매년 결 정 · 고시한다. 또한 $\ulcorner$ 산지관리법」제 4 조에 의 해 구분되는 산지 또는 지역별로 단위면적당 금 액을 달리할 수 있다.

농지보전부담금은 농지의 보전 - 관리 및 조 성을 위한 비용으로 「농지법」 제 38 조에 의해 정 의된다. 농지보전부담금은 「부동산 가격공시 및 감정평가에 관한 법률」에 따른 해당 농지의 개 별공시지가의 범위에서 대통령령으로 정하는 부과기준을 적용하여 산정한 금액으로 한다.

「초지법」제 23 조, 「초지법 시행령」제 16 조의 3 에 의하면 초지의 전용을 하고자 하는 자는 대 체초지조성비를 $r$ 축산법, 제 42 조의 규정에 따 라 축산발전기금에 납입하여야 한다. 초지조성 비 지급기준은 목초의 식생밀도에 따라 다르며, 초지조성단가는 초지 $1 \mathrm{~m}^{2}$ 조성에 필요한 비용 으로서 농림축산식품부장관이 매년 산출·고시 하는 비용을 말한다. 2013년 2월 기준의 초지조 성단비는 경운초지가 5,267 천원/1만m ${ }^{2}$ 이다.
해양생태계에 미치는 영향이 현저하거나 해 양생물다양성의 감소를 초래하는 개발사업을 하는 경우 $\Gamma$ 해양생태계의 보전 및 관리에 관한 법률」제 49 조에 의거하여 해양생태계보전협력 금을 부과 - 징수한다. 부과대상이 되는 사업은 「환경영향평가법」 제 22 조에 따른 영향평가대상 사업 중 공유수면 내에서 이루어지는 개발사업, 「광업법, 제 3 조 제 2 호에 따른 광업 중 대통령령 이 정하는 규모 이상의 공유수면 내 탐사 및 채 굴사업, $\Gamma$ 해양환경관리법, 제 85 조에 따른 해역 이용영향평가 대상사업 중 r골재채취법」제 22 조에 따른 50 만 $^{3}$ 이상의 바다골재채취 및 동법 제 34 조에 따른 바다골재채취단지의 지정, 그 밖 에 해양생태계에 미치는 영향이 현저하거나 해 양자산을 이용하는 공유수면 내의 사업 중 대통 령령으로 정하는 사업이 그 대상이다. 부과금 산 정 방법은 생태계의 훼손면적에 단위면적당 부 과금액과 지역계수를 곱하여 산정 - 부과한다.

개발제한구역의 보전과 관리를 위한 재원을 확보하기 위하여 「개발제한구역의 지정 및 관 리에 관한 특별조치법, 제 21 조에 의거하여 해 제대상지역 개발사업자 중 동법 제 4 조제 6 항에 따라 복구계획을 제시하지 아니하거나 복구를 하지 아니하기로 한 자, 동법 제 12 조제 1 항 단서 또는 제 13 조에 따른 허가를 받은 자에게 부과 징수하는 것을 개발제한구역 보전 부담금이라 한다. 부담금의 산정 기준은 개별공시지가를 기 준으로 산정한다.

\section{2) 국외 유사 법규 및 제도}

현재 $\mathrm{OECD}$ 국가들이 자연자산보전에 적용 하고 있는 경제적 수단은 다양하지만 대부분 보 조금과 환경세 또는 부담금 제도의 형태로 운영 되고 있다(OECD, 1997). 미국의 경우 자연습지 $1 \mathrm{ha}$ 를 매립하는 경우 $2 \mathrm{ha}$ 의 인공습지 조성을 의 무화 하고 있으며, 뉴질랜드와 스웨덴은 개발로 인한 환경피해를 완화 하거나 또는 환경복원을 자체적으로 추진하도록 되어있으며 또는 이에 
Table 2. Type of levies in Korea.

\begin{tabular}{|c|c|c|c|c|}
\hline Levies & \multicolumn{3}{|c|}{ Standard for calculating charges } & Related Act \\
\hline \multirow{5}{*}{$\begin{array}{l}\text { Expenses incurred } \\
\text { in creating } \\
\text { forest replacement } \\
\text { resources }\end{array}$} & \multicolumn{3}{|c|}{$\begin{array}{l}\text { - The area of the mountainous district to be converted or } \\
\text { temporarily used } \times \text { the price per unit area } \\
\text { - The price per unit area: determined and announced by the } \\
\text { Administrator of the Korea Forest Service }\end{array}$} & \multirow{5}{*}{$\begin{array}{l}\text { Management of } \\
\text { mountainous districts } \\
\text { Act } \\
\text { Article } 19\end{array}$} \\
\hline & \multicolumn{2}{|c|}{ Semi-preserved mountainous district } & 3,070 won $/ \mathrm{m}^{2}$ & \\
\hline & \multicolumn{2}{|c|}{ Preserved mountainous district } & 3,990 won $/ \mathrm{m}^{2}$ & \\
\hline & \multicolumn{2}{|l|}{ Restricted area } & 6,140 won $/ \mathrm{m}^{2}$ & \\
\hline & \multicolumn{3}{|l|}{${ }^{*}$ Based on $16^{\text {th }}$ May, 2013} & \\
\hline $\begin{array}{l}\text { Farmland creation } \\
\text { charges }\end{array}$ & \multicolumn{3}{|c|}{$\begin{array}{l}\text { - Diversion area of farmland } \times \text { the amount of farmland creation } \\
\text { charges per unit for each farmland } \\
\text { - Standards for calculating charges: } 30 / 100 \text { of the average amount } \\
\text { of the individually published land prices of farmland by 'Price } \\
\text { announcement of real estate and appraisal Act } \\
\text { - The limit per square meter: within } 50,000 \text { won }\end{array}$} & $\begin{array}{l}\text { Farmland Act } \\
\text { Article } 38 \\
\text { Enforcement } \\
\text { Decree } \\
\text { Article } 53\end{array}$ \\
\hline \multirow{5}{*}{$\begin{array}{l}\text { The cost of } \\
\text { development } \\
\text { of substitute } \\
\text { grassland }\end{array}$} & \multicolumn{3}{|c|}{$\begin{array}{l}\text { - Grassland development cost (the cost required for developing } \\
\text { a grassland of one hectare) }\end{array}$} & \multirow{5}{*}{$\begin{array}{l}\text { Grassland Act } \\
\text { Article } 23\end{array}$} \\
\hline & Ploughed grassland & 5,26 & lousand won/ha & \\
\hline & Non-ploughed grassland & 3,91 & lousand won/ha & \\
\hline & Pasture in forest & 3,79 & lousand won/ha & \\
\hline & \multicolumn{3}{|c|}{${ }^{*}$ Based on $5^{\text {th }}$ February, 2013} & \\
\hline $\begin{array}{l}\text { Marine ecosystem } \\
\text { conservation levy }\end{array}$ & \multicolumn{3}{|c|}{$\begin{array}{l}\text { - The damaged area of ecosystem } \times \text { the amount levied per unit } \\
\text { of area } \times \text { the regional coefficient } \\
\text { - The amount levied per unit of area: } 250 \text { won } / \mathrm{m}^{2}\end{array}$} & $\begin{array}{l}\text { Conservation and } \\
\text { management of marine } \\
\text { ecosystem Act } \\
\text { Article } 49\end{array}$ \\
\hline $\begin{array}{l}\text { Charges for } \\
\text { development } \\
\text {-restricted } \\
\text { areas preservation }\end{array}$ & \multicolumn{3}{|c|}{$\begin{array}{l}\text { - The charges referred to in Article } 21 \text {, Section (1), Subsection } \\
\text { 1: multiplying } 10 / 100 \text { of the average amount of the individually } \\
\text { published land prices of the land per square meter for the Areas } \\
\text { Subject to Lifting by the area of the relevant region }\end{array}$} & $\begin{array}{l}\text { Act on special measures } \\
\text { on designation and } \\
\text { management of } \\
\text { development } \\
\text {-restricted areas } \\
\text { Article } 21\end{array}$ \\
\hline
\end{tabular}

* National Legislation Information Center (http://law.go.kr/)

Statutes of the Republic of Korea (https://elaw.klri.re.kr/)

소요되는 비용을 서식지 복원을 위해 부담하도 록 되어 있다. 스위스에서는 도로건설 사업 등 개발 사업 시행 시 자연회복 조치에 필요한 재 원징수를 통해 이를 자연하천의 조성 등에 투자 하고 있다(Kwan and Yoo, 2000).
독일은 환경법으로 보상원칙(Kompensationsprinzip) 이 규정되어 있다. 이는 부과금의 성격을 지니고 있으며, 환경보호의 관점에서 법률상 허용되지 않는 개발 행위일지라도 환경손실분에 대해서 부담금 혹은 부과금 등 금전적 부담을 취하면 개 
Table 3. Type of subsidy in other countries.

\begin{tabular}{|c|c|c|}
\hline Country & \multicolumn{2}{|c|}{ Value of subsidy } \\
\hline Germany & \multicolumn{2}{|c|}{$\begin{array}{l}\text { - Environment compensation B: } 40 \mathrm{EUR} / \mathrm{ha} \\
\text { - Environment compensation E: } 20 \mathrm{EUR} / \mathrm{ha} \\
\text { - Environment compensation W: } 20 \mathrm{EUR} / \mathrm{ha} \\
\text { - Environment compensation N: } 50 \mathrm{EUR} / \mathrm{ha}\end{array}$} \\
\hline \multirow{4}{*}{ Netherlands } & \multicolumn{2}{|l|}{ - Cost of replacement of forest (Example) } \\
\hline & Dry grasslands of the higher sandy & 43,190.30 EUR/ha \\
\hline & Bunch of poor sandy soils & 48,992.80 EUR/ha \\
\hline & Peatlands & 46,945.75 EUR/ha \\
\hline \multirow{3}{*}{ Japan } & \multicolumn{2}{|l|}{ - Subsidy for afforestation } \\
\hline & Needleleaf tree & $939,000-1,117,000$ Yen/ha \\
\hline & Broadleaf tree & $1,060,000-1,279,000$ Yen/ha \\
\hline
\end{tabular}

발을 인정해주는 제도이다. 하지만 적절한 부과 금액을 결정하기 위한 평가 기준은 없는 실정이 다. 바덴-뷔르템베르크(Baden-Württemberg)주의 경우 산림정비세금(Forest Maintenance Tax)이 부과된다. 이는 자연 자원을 보호, 보전하기 위해 금전적 기부를 요구하는 형식이며, 산림 개발 시 다른 신규조림 등으로 대체가 불가능 할 경우, 산 림 소유자에게 세금이 최소 $0.6 \mathrm{EUR} / \mathrm{ha}$ 에서 최대 토지이용 전환 후의 토지가격의 $10 \%$ 까지 부과 될 수 있다. 또한 산림보전 및 산림기능 복원을 위하 여 산림관리, 산림보호, 산림의 생태적 기능 보전 등의 행위에 대하여 20 50 EUR/ha 정도의 금액 을 지원 해준다(European Forest institute, 2013).

네덜란드의 경우 환경관리법(Wet Milieubeheer, $\mathrm{Wm}$ ) 제7장에 환경영향평가에 대한 내용이 규 정되어 있다. 그 내용은 개발 사업 시, 이로 인 한 환경에의 영향을 회피 또는 저감하여야 하 며, 영향을 미칠 경우 회복 또는 대체 조성을 해 야 한다는 것이다. 대체 조성을 할 경우, 대상 지역의 생태계가 회복될 때까지의 관리비용을 부담해야하며, 일반적으로 대체 조성 후 약 5년 간의 관리비용을 부담한다. 하지만 산림 지역에 조림하는 경우는 약 10 년간의 관리비용을 부담
하며, 대체 조성에 드는 비용은 산림의 경우를 예로 들면 약 $49,000 \mathrm{EUR} / \mathrm{ha}$ 정도이다. 대체 조 성이 불가능할 경우 금전적인 지불방법으로 대 신할 수 있으며, 그 경우 동질의 토지 구입비용 과 토지의 기본적인 정비를 위한 비용, 그리고 대체 조성 지역의 생태계가 회복될 때까지의 관 리비용을 바탕으로 지불금액을 계산하며, 이때 발생된 비용은 녹지기금으로 사용된다(Ministry of Agriculture, Nature and Food Quality, 2007).

일본은 「자연 환경 보전법」제 37 조 원인자 부담원칙에 의해 공사 또는 다른 행위로 인하여 보전 사업의 집행이 필요한 경우 그 원인이 되 는 공사 또는 행위의 시행자에게 보전 사업의 집행에 필요한 비용의 전부 또는 일부를 부담시 킬 수 있다. 하지만 부담금의 징수 방법이나 기 타 필요한 사항은 법령 또는 조례에 의해 결정 된다(Yokohama Tax Study Group, 2007).

조림 및 임도 정비를 위한 지원제도로서는 산 림 정비 기금(조림 보조금)이 있으며, 산림법 제 193조에 따라 국가사업으로 진행되고, 도도부현 (都道府縣, 광역지자체 단위)은 국고 보조금으로 받은 보조금을 사업 주체에게 교부한다. 보조금 은 국비와 현비(縣費), 기초지자체 단위인 시정촌 
비용(市町村費)까지 합계한 사업비에 따라 지급 되며, 도도부현마다 보조 비율이 다르다. 표준 평 가 계수를 적용하는 경우 부담률은 국가가 $51 \%$, 지방이 $17 \%$ 등 총 $68 \%$ 를 보조한다(Ministry of Agriculture, Forestry and Fisheries, 2012).

\section{III. 산림생태계기능 가치 추정 방법}

본 연구에서 산림자원의 가치를 평가한 방법 은 1992년부터 2013년까지의 65건에 대한 기존 산림자원의 가치를 평가한 연구들의 결과를 이 용하여 기존 연구의 결과 및 특성을 분석하고, 그 후 조사된 연구의 평가요인 항목을 선정한 다. 다음 단계로는 선정된 평가요인 항목의 기 능을 가치유형별로 재분류 후, 기능별로 가치를 추정하였다. 또한 시간적 범위가 다른 가치들의 결과에 할인율을 적용하여 동일한 시간적 범위 로 보정을 하였으며, 이 후 단위면적당 연간가 치로 환산하여 산림자원의 기능별 가치를 추정 하고 마지막으로 추정된 단위가치를 이용하여 편익이전 방법으로 산림자원의 전체가치를 추 정하였다.

평가요인 선정 과정은 출처의 객관성, 적용범 위의 일반성, 발행연도의 최근성 등 세 가지의 기준으로 구분하여 평가요인을 분류 및 선정하 였다. 이후 선정된 요인의 생태계서비스 기능별 가치의 이중계산을 방지하기 위하여 생태계서 비스가 제공하는 여러 기능을 사용가치와 비사 용가치로 구분하여 재분류를 진행하였다. 사용 가치는 자원의 직 - 간접적으로 사용하면서 얻 는 가치를 의미한다. 직접사용가치는 임산물과 같은 직접적으로 인간이 이용 가능한 가치를 의 미하며, 간접사용가치는 환경을 직접 사용하지 는 않으나 환경과 생태계의 작용으로 얻게 되는 편익을 의미한다. 산림자원의 생산기능, 유전자 원 등의 공급서비스는 직접사용가치를 추정하 였고, 대기정화, 기후조절, 수질정화, 토사붕괴 방지, 침식조절 등과 같은 조절서비스는 간접사
용가치를 추정하였다. 비사용가치에는 현재는 사용하지 않지만 미래에 사용할 가능성이 있기 때문에 선택이 가능하도록 하는 자원의 보전가 치를 의미하는 선택가치, 자연자산을 직 - 간접 적으로 사용하지 않지만 환경자원이 존재한다 는 사실만으로 얻는 가치인 존재가치, 그리고 마지막으로 인류의 공동 유산 등 앞으로 이용할 계획은 없으나 미래세대를 위하여 보존할 필요 성이 있다고 생각하여 부여하는 유산가치 등으 로 나눌 수 있다(Freeman III, 2003; Choo, 2005;

Kwon, 2012).

각각의 기능별 가치평가 방법은 생산기능의 경우 우리나라 토지 피복도와 임상도를 기반으 로 용재생산액과 잣, 밤, 송이버섯 자료를 이용 하여 임산물 생산에 대한 가치평가를 분석하였 으며, 유전자원제공 기능의 경우 국내 바이오산 업의 연구 - 개발 투자액 중 국내 생물자원 활용 비율을 이용하여 산림 유전자원에 대한 가치를 간접적으로 추정하였다. 수원함양기능의 가치 에 대해서는 다목적댐 건설비와 사용 가능 연한 등을 고려하여 대체비용법으로 추정하였으며, 기후조절기능은 $\mathrm{CO}_{2}$ 회수 및 저장처리비용 등 을 이용하여 가치를 추정하였다. 수질정화기능 은 우리나라 연평균 강우량을 무임목지에서의 부유물질 유출량을 추정하여 산림 전체가 무임 목지가 되었을 때를 가정하여 소요되는 정수비 용을 산림에 의해 발휘되는 수질정화기능으로 간주하여 수질정화기능에 대한 가치평가를 하 였으며, 침식조절기능에 대한 가치평가는 사방 댐 건설비용을 이용하여 분석하였다. 서식처 기 능은 멸종위기종(산양, 반달가슴곰)의 보전기금 한계지불의사금액을 이용하여 서식처 기능에 대한 가치를 평가하였으며, 문화재보전기능은 경주국립공원, 신흥사, 해인사 보전에 대한 지 불의사금액을 이용하여 가치를 추정하였다.

또한 다양한 단위의 연구 결과를 비교하기 위해서 동일한 단위인 단위면적당 연간 가치로 환산하였다. 시간적 범위 또한 평가기준년도가 
각각 다르기 때문에 시간적 범위의 보정을 위 하여 공공사업부분에 적용하는 사회적 할인율 $5.5 \%$ 를 적용하였다. 이후 산림자원에 대한 생 태계서비스 기능별 가치를 추정하고, 산림자원 의 총 가치를 추정하는 방법으로 연구를 진행 하였다.

\section{IV. 생태계보전협력금의 단위면적당 부과액 개선방안}

\section{1. 산림자원 가치평가 결과 및 특성분석}

산림자원의 경우 휴양 및 생태관광 기능을 대 상으로 이루어진 가치추정 연구가 $71 \%$ 로 높은 비중을 차지하고 있으며, 그 연구 대상지는 국 립공원, 자연휴양림, 도립공원 순으로 나타났다. 하지만 산림자원이 제공하는 다양한 간접사용 가치에 대한 연구는 휴양 및 생태관광의 연구에 비해서는 낮은 비중을 보이고 있는 것으로 나타 났다.

산림부분의 선행연구에 사용된 추정기법 측 면에서 보면, 전체 선행연구 중 $69 \%$ 가 가상가 치평가법(CVM)을 사용하였고, $1 \%$ 를 차지하고 있는 컨조인트분석(CE)까지 고려하면 진술선호 법(Stated preference)이 절대적인 다수를 차지하 고 있는 것을 알 수 있다. 다음으로 대체비용법 (RCM) $16 \%$, 여행비용법(TCM) $12 \%$ 의 경향을 보인다.

연구 결과에 나타난 단위는 연구의 대상 또는 목적에 따라 달리 나타났다. 가장 많이 추정된 휴양 및 생태관광 기능을 예로 들면 연구에 사 용된 단위는 '원/방문회수. 인'이 가장 많았으 며, 동시에 '원/년 - 가구'를 원단위로 사용한 연 구도 상당수 존재하였다. 이는 기능의 가치를 추정하는 경우에는 중점에 두는 가치의 종류에 따라 그 단위가 달리 나타났는데, 사용가치에 중점을 두면 ‘원/방문회수 - 인'이, 총가치(사용 가치+비사용가치)에 중점을 둔 연구는 ‘원/년 · 가구’를 단위로 사용하는 경향이 나타났다.

\section{2. 생태계서비스 기능별 가치유형 분류}

수집된 데이터를 출처의 객관성, 적용범위의 일반성, 발행연도의 최근성 등의 기준을 적용하 여 재분류하였다. 출처의 객관성은 학술지(등재 이상), 중앙정부 및 연구소 보고서, 지방정부 보 고서 순으로 분류하였으며, 적용범위의 일반성 은 국내 전국의 적용가능성, 특정지역의 적용가 능성 또는 국외 지역의 적용가능성의 순서를 기 준으로 분류하였다. 발행연도의 최근성은 2005 년 이후, 1995 2004년, 1995년 이전의 기준을 적용하여 분류하였다.

분류 결과 공급서비스는 수원함양기능, 임상 물 생산기능, 조절서비스는 대기정화, 기후조절, 수질정화, 토사붕괴방지, 침식조절 기능, 지원서 비스는 생물다양성, 문화서비스는 휴양/생태관 광, 문화/전통유산 기능 등으로 설정하였다.

각각의 서비스별 가치분류는 공급서비스 중 수원함양은 간접사용가치, 임산물생산은 직접 사용가치로 분류하였으며, 조절서비스는 모두 간접사용가치, 지원서비스는 비사용가치중 존 재가치, 문화서비스는 간접사용가치와 비사용 가치를 모두 가지는 것으로 나타났다. 이는 재 화나 서비스가 제공하는 모든 편익을 포함하는 총경제적가치의 개념을 사용하여 구분된 기능 에 중에서 가치화 할 수 있는 것은 어떤 것이 있 는지 판단하였으며 이를 바탕으로 기능별 가치 를 추정하였다.

\section{3. 산림자원 기능별 가치추정 및 단위면적당 부과액 개선방안}

산림자원이 제공하는 생태계서비스의 기능은 임목생산, 수원함양, 유전자원제공, 대기정화, 기후조절, 수질정화, 침식조절, 토사붕괴방지, 서식처, 휴양, 문화에 대한 기능으로 선정되었 다. 산림자원의 가치추정 결과를 사용가치와 비 사용가치를 나누어서 분석하였을 때, 가치추정 결과 비사용가치 $(68 \%)$ 가 가장 높게 평가 되었 고, 그다음으로 간접사용가치(27\%), 직접사용가 
Table 4. Unit value of ecosystem function.

(Unit: $\mathrm{KRW} / \mathrm{m}^{2} \cdot$ year)

\begin{tabular}{|c|c|c|c|c|c|}
\hline \multirow{2}{*}{ Ecosystem service } & \multirow{2}{*}{\multicolumn{2}{|c|}{ Function }} & \multicolumn{2}{|c|}{ Use Value } & \multirow{2}{*}{ Non-use Value } \\
\hline & & & Direct & Indirect & \\
\hline \multirow{4}{*}{ Provision } & \multicolumn{2}{|c|}{ Water resources } & - & 286.8 & - \\
\hline & \multicolumn{2}{|c|}{ Generic resources } & 3.7 & - & - \\
\hline & \multirow{2}{*}{ Product } & Timber & 18.4 & - & - \\
\hline & & Non-timber & 40.9 & - & - \\
\hline \multirow{5}{*}{ Regulation } & \multicolumn{2}{|c|}{ Air purification } & - & 18.2 & - \\
\hline & \multicolumn{2}{|c|}{ Climate regulation } & - & 68.0 & - \\
\hline & \multicolumn{2}{|c|}{ Water purification } & - & 121.0 & - \\
\hline & \multicolumn{2}{|c|}{ Prevent landslide } & - & 96.1 & - \\
\hline & \multicolumn{2}{|c|}{ Erosion regulation } & - & 263.2 & - \\
\hline Supporting & \multicolumn{2}{|c|}{ Habitat } & - & - & 366.7 \\
\hline \multirow{2}{*}{ Cultural } & \multicolumn{2}{|c|}{ Recreation / Ecotourism } & 116.9 & - & - \\
\hline & \multicolumn{2}{|c|}{ Cultural / Traditional heritage } & 279.0 & - & 1815.1 \\
\hline \multicolumn{3}{|c|}{ Value } & 458.9 & 853.3 & $2,181.8$ \\
\hline \multicolumn{3}{|c|}{ Total value } & & & $3,494.0$ \\
\hline
\end{tabular}

치 $(5 \%)$ 순으로 나타났다.

산림자원의 수원함양 기능과 생산서비스는 직접사용가치를 추정하였고, 대기정화, 기후조 절, 수질정화, 토사붕괴방지, 침식조절 등과 같 은 조절서비스는 간접사용가치 값이 추정되었 다. 생물다양성 기능의 경우 간접사용가치와 비 사용가치가 모두 추정되었으며, 문화서비스의 휴양 및 생태관광 기능은 직접사용가치, 문화 및 전통유산 기능은 직접사용가치와 비사용가 치가 모두 추정되었다. 분석결과 산림자원이 연 간 제공하는 기능별 단위면적당 가치추정액은 다음 Table 4과 같다.

산림자원의 기능별 가치 추정 결과, 산림자원 이 제공하는 가치는 연간 약 3,500 원 $/ \mathrm{m}^{2}$ 으로 나 타났으며, 사용가치는 약 1,300 원 $/ \mathrm{m}^{2}$, 비사용가 치는 약 2,200 원 $/ \mathrm{m}^{2}$ 으로 나타났다. 이는 산림을 바라보는 관점이 직접적인 이용보다는 간접적 인 이용에 중점을 두는 것으로 볼 수 있으며, 생 산관리의 측면보다는 보전관리에 높은 가치를
두는 것으로 나타났다.

국립산림과학원에서 수행한 산림의 공익기능 계량화 연구에 의하면 2010년 기준으로 우리나 라 산림의 총 가치는 약 109조원으로 나타났으 며(Korea Forest Service) 이를 산림 전체면적인 $6,374,875 \mathrm{ha}$ 로 나누면 약 1,700 원 $/ \mathrm{m}^{2}$ 로 나타났 다. 본 연구결과와 비교하여보면 총가치는 국립 산림과학원의 결과보다 약 2 배 정도 크게 나타 났지만 이는 비사용가치까지 추정하였기 때문 으로 판단된다.

본 연구결과를 이용한다면 현재의 생태계보전 협력금의 단위면적당 부과액은 현행 250 원 $/ \mathrm{m}^{2}$ 에 서 약 3,500 원 $/ \mathrm{m}^{2}$ 까지 증가시킬 수 있을 것이다. 하지만 국민정서 등을 고려할 때 총가치가 아닌 약 1,300 원 $/ \mathrm{m}^{2}$ 인 사용가치만이라도 반영시킬 수 있도록 노력해야 할 것이다. 또한 산림자원이 매년 제공하는 가치임을 고려한다면 1 회성에 해당하는 생태계보전협력금의 단위면적당 부과 액으로도 적정하다고 판단된다. 


\section{V. 결 론}

현재의 생태계보전협력금은 2001년에 250원 $/ \mathrm{m}^{2}$ 으로 결정된 후 지금까지 유지되고 있다. 또한 r자 연환경보전법」제 46 조 제6항에는 단위면적당 부 과금액은 훼손된 생태계의 가치를 기준으로 한다 고 명시되어 있으나, 생태계의 가치가 250 원 $/ \mathrm{m}^{2}$ 이라는 근거는 찾아볼 수 없다. 국내 유사 법규 를 살펴보더라도 대체산림자원 조성비는 약 $3,000 \sim 6,000$ 원 $/ \mathrm{m}^{2}$, 농지보전부담금은 공시지가 (상한 50,000 원 $/ \mathrm{m}^{2}$ ), 대체초지 조성비는 약 1,000 원 $/ \mathrm{m}^{2}$, 개발제한구역 보전 부담금 역시 공 시지가를 적용하는 등 생태계보전협력금보다 단위면적당 금액이 높거나, 최소한 물가는 반영 되어 있다. 또한 다른 부처의 경우 매년 관련부 처 장관이 제반 여건을 반영한 단위금액을 고시 하지만 생태계보전협력금은 그러지 못하고 있 는 실정이다.

외국의 사례와 비교해 보아도 네덜란드의 경 우 대체 조성비용으로 약 $6,000 \sim 7,000$ 원 $/ \mathrm{m}^{2}$ 정 도 부과하고 있으며, 일본의 경우 산림 보호를 위해 최소 약 1,000 원 $/ \mathrm{m}^{2}$ 에서 최대 약 1,400 원 $/ \mathrm{m}^{2}$ 까지 보조금을 지급하고 있다.

Ministry of Environment(2007)에서 발표한 보 고서에 의하면 환경부에서도 2000년에 이미 250 원 $/ \mathrm{m}^{2}$ 이라는 금액의 문제점을 파악하고 있었으 며, 당시 한국환경경제학회에서 500 원 $/ \mathrm{m}^{2}$ 의 재 산정 금액을 제시하였으나 반영되지 못하였다. 또한 한국개발연구원에서 주로 사용하는 할인율 연 $10 \%$ 를 적용하더라도 2001 년의 250 원 $/ \mathrm{m}^{2}$ 는 2013년 현재 약 800 원 $/ \mathrm{m}^{2}$ 의 금액으로 적용할 수 있으나 역시 반영을 하지 못하고 있다.

이러한 사례들과 본 연구 결과를 이용한다면 현재 생태계보전협력금의 단위면적당 부과액을 사용가치 수준인 1,300 원 $/ \mathrm{m}^{2}$ 까지는 올릴 여지가 남아있는 것이다.

본 연구에서는 다양한 용도지구에 부과되고 있는 생태계보전협력금이지만, 산림자원의 가
치만 반영한 한계점을 지니고 있다. 하지만 산 림자원의 가치만 하더라도 약 3,500 원 $/ \mathrm{m}^{2}$ 의 가 치가 있다는 것을 밝혔으며, 이는 초지, 습지 등 다른 자연자산의 가치가 평가되면 생태계보전 협력금의 단위면적당 부과금액은 더 상승할 여 지가 남아있는 것으로 판단된다.

현재의 생태계보전협력금은 오히려 준조세의 성격으로 변화하는 등 개발을 막기 위한 원래의 취지에 부합하다. 생물다양성협약, 생태계서비 스 등 생태계의 가치가 재조명되고 있는 시점에 서 생태계보전협력금의 부과 방식의 개선은 제 도의 취지를 살리기 위해서도 필요하다. 하지만 자연자산의 가치를 반영한다면 현재의 생태계 보전협력금 징수액은 많이 늘어날 것이다. 이러 한 경우 현재와 같이 특별회계에 편입시켜 사용 할 것이 아니라 본래의 징수 목적에 맞도록 훼 손지역의 복원이나 혹은 복원사업, 대체 생태계 조성을 위한 토지매입자금으로 사용하는 등의 제도적 개선 또한 동반되어야 할 것이다.

\section{인 용 문 헌}

Chiba Prefecture. 2013. Afforestation subsidy standard rate tables on 2013, Japan.

Choo, Bong-Kyu. 2005. Introduction to economics of land, resources and environmental, Seoul National University Press

European Forest institute. 2013. Integration of Nature Protection in Forest Policy in BadenWürttemberg, Germany.

Fisher, B. · Turner, R. K. and Morling, P. 2009. "Defining and classifying ecosystem services for decision making", Ecological economics, 68(2009): 643-653.

Freeman III, A. M. 2003. The Measurement of Environmental and Resource Value: Theory and Methods 2nd ed', An RFF Press book, Washington, DC. 
Korea Forest Service, Nonmarket valuation of forest resources on 2010 in Korea, http:// www.forest.go.kr.

Kwak, Seung-Jun and Yoo, Seung-Hoon. 2000. Redesigning A Program of Ecosystem Conservation Fund, Environmental and Resource Economics Review, 9(3); 563-587.

Kwon, Oh-Sang. 2012. Environmental economics 2nd edition, Seoul: Pakyoungsa.

Lee, Yang-Joo. 2009. A study on management system of ecosystem conservation fund, Gyeonggi Research Institute.

Ministry of Agriculture, Forestry and Fisheries, 2012. Forest environment improvement project, Japan.

Ministry of Agriculture, Nature and Food Quality, 2007. Spelregels EHS: Beleidskader voor compensatiebeginsel, EHS-saldobenadering en herbegrenzen-EHS, Een gezamenlijke uitwerking van rijk en provincies, Netherlands.

Ministry of Environment, 2007. A study on the improvement of cooperation charge on conservation of ecosystem.

National Legislation Information Center (http:// law.go.kr/).

OECD, 1997. Evaluating \&anomie Instruments for Environmental Policy, Paris.

Seppelt, R. · Dormann, C. F. - Eppink, F. V. • Lautenbach, S. and Schmidt, S. 2011. "A quantitative review of ecosystem service studies: approaches, shortcomings and the road ahead", Journal of Applied Ecology, 48: 630-636.

Statutes of the Republic of Korea (http://elaw. klri.re.kr/).

Yokohama Tax Study Group. 2007. Using taxation autonomy for conservation and creation of green, Japan. 